Check for updates

Cite this: RSC Adv., 2019, 9, 5158

Received 25th January 2019

Accepted 6th February 2019

DOI: $10.1039 / c 9 r a 00653 b$

rsc.li/rsc-advances

\section{An efficient one pot three-component synthesis of 2,4,6-triarylpyridines using triflimide as a metal- free catalyst under solvent-free conditions $\uparrow$}

\author{
Hongshe Wang, (D) * Weixing Zhao, Juan Du, Fenyan Wei, Qi Chen and Xiaomei Wang \\ A simple and efficient protocol developed for one pot three-component synthesis of 2,4,6-triarylpyridines \\ from aromatic aldehydes, substituted acetophenones and ammonium acetate using the versatile super \\ Brønsted acid triflimide $\left(\mathrm{HNTf}_{2}\right)$ as an effective catalyst is described. The reactions proceed well in the \\ presence of $1 \mathrm{~mol} \%$ of $\mathrm{HNTf}_{2}$ at $80{ }^{\circ} \mathrm{C}$ under solvent-free conditions and provide the corresponding \\ triarylpyridines in good to excellent yields. The method reported has several advantages such as a metal- \\ free and commercially available catalyst, mild reaction conditions and lower loading of catalyst.
}

\section{Introduction}

Substituted 2,4,6-triarylpyridines have been extensively exploited as chemosensors, ${ }^{\mathbf{1}}$ photosensitizers, ${ }^{\mathbf{2}}$ and intermediates in the synthesis of therapeutic drugs, insecticides, herbicides, and surfactants. ${ }^{3}$ Consequently, various synthetic methods have been developed for the synthesis of 2,4,6-triarylpyridines, ${ }^{4}$ such as the coupling of aryl aldehydes with aromatic keto-oxime acetates, ${ }^{5}$ oxidative cleavage of $\mathrm{C}-\mathrm{N}$ bonds of benzyl amines with aromatic ketones, ${ }^{6}$ and the reactions of aromatic ketones with benzyl amines, ${ }^{7}$ acetophenoneoximes with aldehydes ${ }^{8}$ or epoxy styrenes, ${ }^{9}$ benzyl halides with acetophenones, ${ }^{10}$ and chalcones with enaminones. ${ }^{11}$ The cyclo-condensation reaction of acetophenones, benzaldehydes and ammonium acetate is known as one of the most conventional pathways for the synthesis of 2,4,6-triarylpyridines in the presence of various catalysts such as PEG $_{1000}$-DAIL, ${ }^{12}$ ionic liquids, ${ }^{13}$ PFPAT, $^{14}$ $\mathrm{TrCl},{ }^{15} \mathrm{MIL}-101-\mathrm{SO}_{3} \mathrm{H},{ }^{16} \mathrm{DPTA}^{17} \mathrm{ZrOCl}_{2}{ }^{18} \mathrm{TiO}_{2}-\mathrm{SO}_{3} \mathrm{H},{ }^{19} \mathrm{TCT}^{20}$ or $\mathrm{Fe}_{3} \mathrm{O}_{4} @ \mathrm{TiO}_{2} @ \mathrm{O}_{2} \mathrm{PO}_{2}\left(\mathrm{CH}_{2}\right)_{2} \mathrm{NHSO}_{3} \mathrm{H},{ }^{21}$ or without a catalyst. $^{22}$ Although each of the above methods has its own merits, most of these methods are associated with certain drawbacks such as commercially unavailable catalysts, use of metals as catalysts and high reaction temperatures. To avoid such drawbacks, development of more simple and efficient protocols is still in demand.

Nowadays, one pot multicomponent reactions (MCRs) have received much attention for the synthesis of diverse compounds and contribute to sustainability by simplifying the synthetic route. ${ }^{23}$ MCRs combine three or more starting reagents at a time in the same pot to create the target molecule since there is no

College of Chemistry and Chemical Engineering, Baoji University of Arts and Sciences, Baoji 721013, China.E-mail: baojizwx@126.com

$\dagger$ Electronic supplementary information (ESI) available. See DOI: 10.1039/c9ra00653b need of separating intermediate which help to reduce the energy consumption, solvent waste and reaction time and thus have the advantages of synthetic efficiency, simplicity, atom economy.

Triflimide ( $\mathrm{HNTf}_{2}$ ), also known as bis(trifluoromethanesulfonyl) imide, is a commercially available white crystalline solid and highly versatile super Brønsted acid. Owing to its strong acidity as well as good compatibility with organic solvents, it has been widely employed as an exceptional catalyst in a wide range of organic reactions. ${ }^{24}$ Because of the presence of two strongly electronwithdrawing trifluoromethanesulfonyl groups, triflimide belongs to the superacid family. In recent years, specifically, triflimide has been extensively demonstrated as a superb catalyst in miscellaneous cycloaddition reactions such as $[2+2],{ }^{25}[3+2],{ }^{26}[4+2],,^{27}[3+$ $3],{ }^{28}[4+3],,^{29}[6+2]$ (ref. 30) and $[2+2+2]$ (ref. 31) cycloadditions. It is found that triflimide has also been used as a catalyst in numerous other organic reactions such as formation of oxime ethers, ${ }^{32}$ Mukaiyama aldol reaction, ${ }^{33}$ alkylation, ${ }^{34}$ synthesis of indanes and tetralins, ${ }^{35}$ allyl-allyl cross-coupling, ${ }^{36} \mathrm{C}-\mathrm{C}$ bond formation $^{37}$ and Nazarov reaction. ${ }^{38}$ In view of the efforts toward development of the potential of $\mathrm{HNTf}_{2}$ as a catalyst, herein, we report an efficient one pot three-component synthesis of 2,4,6-triarylpyridines (Scheme 1).

\section{Results and discussion}

In order to optimize the reaction conditions, the reaction of acetophenone, benzaldehyde and ammonium acetate was selected as a model reaction. The effect of solvent (Table 1), catalyst loading (Table 2), and temperature (Table 3) were monitored. The model reaction was examined in various solvent such as DMF, DMSO, PEG-400, toluene and under solvent-free conditions. Studies of solvent effect on the activity of catalyst reveal that the best yield was achieved under solvent-free conditions (entry 8 , Table 1 ). Only $21 \%$ yield of the product was obtained in the absence of the catalyst (entry 1, Table 2). 
Scheme $1 \mathrm{HNTf}_{2}$ catalyzed one pot three-component synthesis of 2,4,6-triarylpyridines.

Table 1 Effect of solvent on the synthesis of 2,4,6-triphenylpyridine ${ }^{a}$

\begin{tabular}{lll}
\hline Entry & Solvent & Yield $^{b}(\%)$ \\
\hline 1 & Acetonitrile & 23 \\
2 & DMF & 64 \\
3 & DMSO & 56 \\
$4^{c}$ & $\mathrm{CH}_{2} \mathrm{Cl}_{2}$ & 57 \\
5 & $\mathrm{PEG}^{c} 400$ & 66 \\
6 & Toluene & 52 \\
7 & $\mathrm{H}_{2} \mathrm{O}$ & 62 \\
8 & None & 93
\end{tabular}

${ }^{a}$ Reaction condition: benzaldehyde $(1 \mathrm{mmol})$, acetophenone $(2 \mathrm{mmol})$, ammonium acetate $(1.5 \mathrm{mmol})$, solvent $(3 \mathrm{~mL}), \operatorname{HNTf}_{2}(1 \mathrm{~mol} \%)$ at $80^{\circ} \mathrm{C}$ for $50 \mathrm{~min} .{ }^{b}$ Isolated yield. ${ }^{c}$ Reaction was performed under reflux condition.

Table 2 Effect of catalyst loading on synthesis of 2,4,6triphenylpyridine ${ }^{a}$

\begin{tabular}{lll}
\hline Entry & Catalyst loading $(\mathrm{mol} \%)$ & Yield $^{b}(\%)$ \\
\hline 1 & None & 21 \\
2 & 0.1 & 43 \\
3 & 0.5 & 79 \\
4 & 1 & 93 \\
5 & 1.5 & 93
\end{tabular}

${ }^{a}$ Reaction condition: benzaldehyde $(1 \mathrm{mmol})$, acetophenone $(2 \mathrm{mmol})$, ammonium acetate $(1.5 \mathrm{mmol}), \mathrm{HNTf}_{2}$ catalyst at $80^{\circ} \mathrm{C}$ for 50 min under solvent-free conditions. ${ }^{b}$ Isolated yield.

When $0.1 \mathrm{~mol} \%$ of catalyst was used in model reaction, the corresponding 2,4,6-triphenylpyridine product was isolated in $43 \%$ yield. When the amount of catalyst has been increased from 0.1 to $0.5 \mathrm{~mol} \%$, 2,4,6-triphenylpyridine was obtained in $79 \%$ yield and the best performance was obtained when $1 \mathrm{~mol} \%$ of catalyst was used (entry 4, Table 2). Further increase in catalyst concentration did not show any significant effect on yield (entry 5 , Table 2). At room temperature a useful conversion was not observed (entry 1, Table 3). However, the productivity increased on raising the temperature. The best results were obtained at $80{ }^{\circ} \mathrm{C}$ (entry 4 , Table 3 ).

On the basis of the above results, the catalytic activity of $\mathrm{HNTf}_{2}$ was further explored for various aromatic aldehydes and substituted acetophenones in the presence of $1 \mathrm{~mol} \%$ of catalyst at $80{ }^{\circ} \mathrm{C}$ under solvent-free conditions. The results are summarized in Table 4 . These results show that the reactions
Table 3 Effect of temperature on the synthesis of 2,4,6triphenylpyridine ${ }^{a}$

\begin{tabular}{lll}
\hline Entry & Temp. $\left({ }^{\circ} \mathrm{C}\right)$ & Yield $^{b}(\%)$ \\
\hline 1 & Room temp. & - \\
2 & 45 & 36 \\
3 & 60 & 67 \\
4 & 80 & 93 \\
5 & 85 & 93
\end{tabular}

${ }^{a}$ Reaction condition: benzaldehyde ( $\left.1 \mathrm{mmol}\right)$, acetophenone ( $\left.2 \mathrm{mmol}\right)$, ammonium acetate $(1.5 \mathrm{mmol}), \mathrm{HNTf}_{2}(1 \mathrm{~mol} \%)$ at different temperature for $50 \mathrm{~min}$ under solvent-free conditions. ${ }^{b}$ Isolated yield.

are equally facile with both electron-donating and electronwithdrawing substituents on the aromatic ring, and all products are obtained in good yields.

A probable mechanism for the synthesis of 2,4,6-triarylpyridines has been proposed in Scheme 2. $\mathrm{HNTf}_{2}$ acts as an efficient Brønsted acid catalyst by activating the carbonyl group of an aromatic aldehyde and a substituted acetophenone to undergo aldol condensation to form a 1,3-diaryl-2-propen-1-one A, which further underwent Michael addition with substituted acetophenone to yield an intermediate B. Intermediate B is then cyclized and dehydrogenated to afford the title product 3 .

The efficiency of the catalyst was determined by comparison with other catalytic systems. It gives a better yield at lower temperature (Table 5).

\section{Conclusions}

In summary, we have disclosed that $\mathrm{HNTf}_{2}$ works as a powerful Brønsted acid catalyst for the one pot three-component synthesis of 2,4,6-triarylpyridines from aromatic aldehydes, substituted acetophenones and ammonium acetate under solvent-free conditions. Advantages of this methodology are use of metal-free and commercially available catalyst, simple experimental and work up procedure, high yields, mild reaction conditions and lower loading of catalyst compared with other methods. The methodology requires $1 \mathrm{~mol} \%$ of $\mathrm{HNTf}_{2}$ catalyst, but it is not reused. This is a huge limitation.

\section{Experimental}

\section{Materials and instrumentation}

Materials obtained from commercial suppliers were used as received unless mentioned otherwise. All solvents were dried by 
<smiles>[R7]c1ccc(C(=O)[CH+][R]2ccc(C(C)=O)cc2)cc1</smiles>

1<smiles>c1ccc(-c2cc(-c3ccccc3)nc(-c3ccccc3)c2)cc1</smiles>

3a ( $93 \%, 50 \mathrm{~min})$<smiles>Brc1ccc(-c2cc(-c3ccccc3)cc(-c3ccc(Br)cc3)n2)cc1</smiles><smiles>Fc1ccc(-c2cc(-c3ccc(F)cc3)nc(-c3ccc(F)cc3)c2)cc1</smiles>

$3 \mathrm{~g}(96 \%, 30 \mathrm{~min})$<smiles>c1ccc(-c2cc(-c3ccc4c(c3)OCO4)nc(-c3ccc4c(c3)OCO4)c2)cc1</smiles>

3j $(89 \%, 60$ min $)$

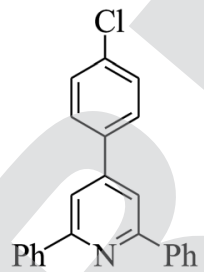

3m $(95 \%, 40$ min $)$

2<smiles>Cc1ccc(-c2cc(-c3ccccc3)cc(-c3ccc(C)cc3)n2)cc1</smiles>

3b $(88 \%, 50 \mathrm{~min})$<smiles>Brc1ccccc1-c1cc(-c2ccccc2)cc(-c2ccccc2Br)n1</smiles>

3e $(95 \%, 40 \mathrm{~min})$<smiles>O=[N+]([O-])c1ccc(-c2cc(-c3ccccc3)cc(-c3ccc([N+](=O)[O-])cc3)n2)cc1</smiles><smiles>c1ccc(-c2cc(-c3ccccn3)nc(-c3ccccn3)c2)cc1</smiles>

3k $(90 \%, 45 \mathrm{~min})$<smiles>Fc1ccc(-c2cc(-c3ccccc3)nc(-c3ccccc3)c2)cc1</smiles>

3n (93\%, 40 min)<smiles>[R][R]1ccc(-c2cc(-c3c#[R]ccc3)cc(-c3ccccc3)n2)cc1</smiles>

3a-u

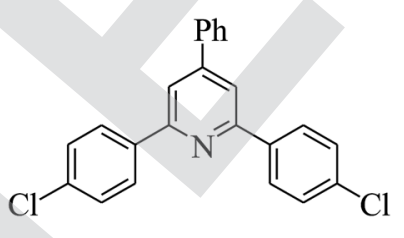

3c $(95 \%, 30 \mathrm{~min})$<smiles>Brc1cccc(-c2cc(-c3ccccc3)cc(-c3cccc(Br)c3)n2)c1</smiles>

3f $(96 \%, 30 \mathrm{~min})$<smiles>COc1ccc(-c2cc(-c3ccccc3)cc(-c3ccc(OC)cc3)n2)cc1</smiles><smiles>Cc1ccc(-c2cc(-c3ccccc3)nc(-c3ccccc3)c2)cc1</smiles>

31 ( $84 \%, 30 \mathrm{~min})$<smiles>Fc1cccc(-c2cc(-c3ccccc3)nc(-c3ccccc3)c2)c1</smiles>

3o $(93 \%, 40 \mathrm{~min})$ 


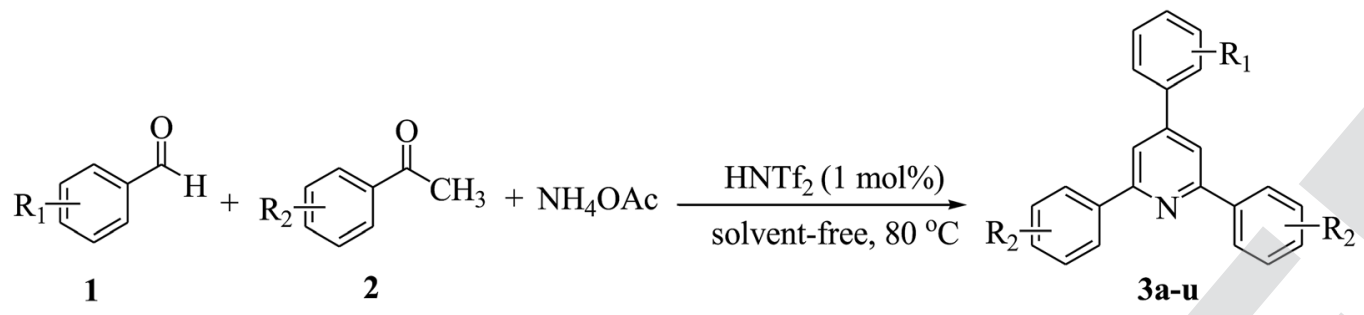<smiles>Brc1cccc(-c2cc(-c3ccccc3)nc(-c3ccccc3)c2)c1</smiles>

$3 \mathbf{p}(95 \%, 45 \mathrm{~min})$<smiles>COc1ccc(-c2cc(-c3ccc(C)cc3)cc(-c3ccc(OC)cc3)n2)cc1</smiles><smiles>Brc1ccc(-c2cc(-c3ccccc3)nc(-c3ccccc3)c2)cc1</smiles>

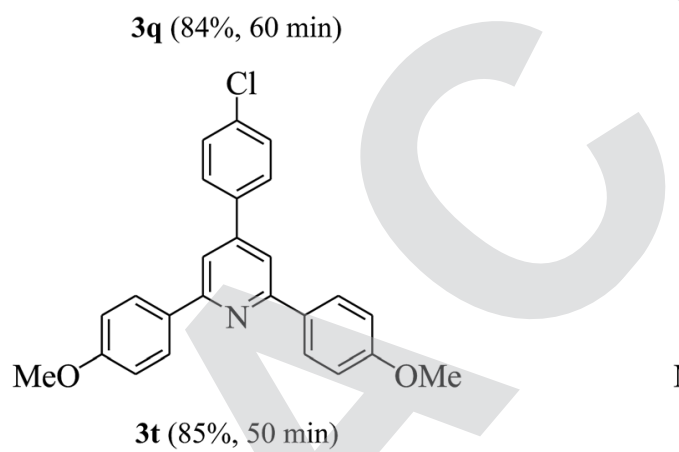

${ }^{a}$ Reaction conditions: $\operatorname{HNTf}_{2}(1 \mathrm{~mol} \%)$, aldehydes $(1 \mathrm{mmol})$, acetophenones $(2 \mathrm{mmol})$, ammonium acetate $(1.5 \mathrm{mmol}), 80{ }^{\circ} \mathrm{C} .{ }^{b}$ Isolated yields.

standard procedures. Melting points were determined on an XT4A electrothermal apparatus equipped with a microscope and are uncorrected. NMR spectra were recorded on a Bruker Avance 400 spectrometer in $\mathrm{CDCl}_{3}$.

\section{General procedure for the synthesis of 2,4,6-triarylpyridine}

A mixture of aromatic aldehyde $(1 \mathrm{mmol})$, acetophenone (2 mmol), ammonium acetate $(1.5 \mathrm{mmol})$ and $\mathrm{HNTf}_{2}(1 \mathrm{~mol} \%)$ was stirred at $80{ }^{\circ} \mathrm{C}$ for $30-60 \mathrm{~min}$. The reaction was monitored by<smiles>[R1]c1cccc(/C=C/C(=O)c2ccc[R1](CC)c2)c1</smiles><smiles>[R17]c1ccc(C(=C)O)cc1</smiles><smiles>[R2][R4]1ccc(C(=O)CC(CC(=O)c2ccc([R4])cc2)c2cccc[R]2[H])cc1</smiles>

B<smiles>[R][R]1ccccc1-c1cc(-c2ccc([R2])cc2)nc(-c2ccc(N)cc2)c1</smiles>

Scheme 2 A plausible reaction mechanism. 
Table 5 Comparison of efficiency of $\mathrm{HNTf}_{2}$ with reported catalytic methods under solvent-free conditions

\begin{tabular}{|c|c|c|c|}
\hline Entry & Conditions & Yield (\%) & Ref. \\
\hline 1 & $120^{\circ} \mathrm{C}, 3.5-7 \mathrm{~h}, \mathrm{H}_{14}\left[\mathrm{NaP}_{5} \mathrm{~W}_{30} \mathrm{O}_{110}\right]$ & $50-98$ & 39 \\
\hline 2 & $120^{\circ} \mathrm{C}, 4-6 \mathrm{~h}, \mathrm{HClO}_{4} / \mathrm{SiO}_{2}$ & $68-88$ & 40 \\
\hline 3 & $120^{\circ} \mathrm{C}, 15-120 \mathrm{~min}, \mathrm{BaCl}_{2} /$ nano- $\mathrm{SiO}_{2}$ & $70-94$ & 41 \\
\hline 4 & $120^{\circ} \mathrm{C}, 6 \mathrm{~h}, \mathrm{I}_{2}(20 \mathrm{~mol} \%)$ & $48-61$ & 42 \\
\hline 5 & $120{ }^{\circ} \mathrm{C}, 1.5-3.5 \mathrm{~h},\left[\mathrm{HO}_{3} \mathrm{~S}\left(\mathrm{CH}_{2}\right)_{4} \mathrm{mim}\right] \mathrm{HSO}_{4}(20 \mathrm{~mol} \%)$ & $82-93$ & $13 a$ \\
\hline 6 & $130^{\circ} \mathrm{C}, 4-7.5 \mathrm{~h}$, wet TCT $(5 \mathrm{~mol} \%)$ & $58-86$ & 20 \\
\hline 7 & $120^{\circ} \mathrm{C}, 4-7 \mathrm{~h}$, DPAT $(2 \mathrm{~mol} \%)$ & $51-96$ & 17 \\
\hline 8 & $130{ }^{\circ} \mathrm{C}, 1-6 \mathrm{~h}$, without catalyst & $60-86$ & 22 \\
\hline 9 & $110^{\circ} \mathrm{C}, 5-9 \mathrm{~min}, \mathrm{MW}$, without catalyst & $80-95$ & 43 \\
\hline 10 & $110^{\circ} \mathrm{C}, 80-150 \mathrm{~min}, n$-TSA & $82-96$ & 19 \\
\hline 11 & $80{ }^{\circ} \mathrm{C}, 30-60 \mathrm{~min}, \operatorname{HNTf}_{2}(1 \mathrm{~mol} \%)$ & $81-96$ & This \\
\hline
\end{tabular}

TLC (petroleum ether $:$ ethyl acetate $=7: 3$, v/v). After completion, the reaction mixture was poured in ice water $(5 \mathrm{~mL})$ and the precipitated solid was collected by filtration, washed with distilled water $(20 \mathrm{~mL})$ and dried. The crude product was recrystallized from $95 \%$ ethanol $(5 \mathrm{~mL})$ to give the corresponding pure product. All the products were characterized by ${ }^{1} \mathrm{H}$ NMR and ${ }^{13} \mathrm{C}$ NMR spectroscopy.

\section{Conflicts of interest}

There are no conflicts to declare.

\section{Acknowledgements}

The authors gratefully acknowledge the financial support provided by Shaanxi Key Laboratory for Phytochemistry (17JS008) and Baoji University of Arts and Sciences (No. ZK14008).

\section{Notes and references}

1 A. G. Fang, J. V. Mello and N. S. Finney, Tetrahedron, 2004, 60, 11075.

2 A. Islam, H. Sugihara and H. Arakawa, J. Photochem. Photobiol., A, 2003, 158, 131.

3 C. Doebelin, P. Wagner, F. Bihel, N. Humbert, C. A. Kenfack, Y. Mely, J. J. Bourguignon and M. Schmitt, J. Org. Chem., 2014, 79, 908.

4 (a) C. Allais, J. M. Grassot, J. Rodriguez and T. Constantieux, Chem. Rev., 2014, 114, 10829; (b) J. Shen, D. Cai, C. Kuai, Y. Liu, M. Wei, G. Cheng and X. Cui, J. Org. Chem., 2015, 80, 6584 .

5 Z. H. Ren, Z. Y. Zhang, B. Q. Yang, Y. Y. Wang and Z. H. Guan, Org. Lett., 2011, 13, 5394.

6 (a) H. Huang, X. Ji, W. Wu, L. Huang and H. Jiang, J. Org. Chem., 2013, 78, 3774; (b) K. Gopalaiah, D. C. Rao, K. Mahiya and A. Tiwari, Asian J. Org. Chem., 2018, 7, 1872.

7 R. S. Rohokale, B. Koenig and D. D. Dhavale, J. Org. Chem., 2016, 81, 7121.

8 S. Mahernia, M. Mahdavi and M. Adib, Synlett, 2014, 25, 1299.
9 S. Mahernia, M. Adib, M. Mahdavi and M. Nosrati, Tetrahedron Lett., 2014, 55, 3844.

10 M. Adib, N. Ayashi and P. Mirzaei, Synlett, 2016, 27, 417.

11 H. Zhang, J. Shen, G. Cheng, B. Wu and X. Cui, Asian J. Org. Chem., 2018, 7, 1089.

12 Y. M. Ren, Z. Zhang and S. Jin, Synth. Commun., 2016, 46, 528.

13 (a) A. Davoodnia, M. Bakavoli, R. Moloudi, N. TavakoliHoseini and M. Khashi, Monatsh. Chem., 2010, 141, 867; (b) S. P. Satasia, P. N. Kalaria and D. K. Raval, RSC Adv., 2013, 3, 3184; (c) H. Behmadi, S. Naderipour, S. M. Saadati, M. Barghamadi, M. Shaker and N. Tavakoli-Hoseinia, J. Heterocycl. Chem., 2011, 48, 1117.

14 N. Montazeri and S. Mahjoob, Chin. Chem. Lett., 2012, 23, 419.

15 A. R. Moosavi-Zare, M. A. Zolfigol and Z. Rezanejad, Can. J. Chem., 2016, 94, 626.

16 M. B. Boroujeni, A. Hashemzadeh, M. T. Faroughi, A. Shaabani and M. M. Amini, RSC Adv., 2016, 6, 100195.

$17 \mathrm{~J} . \mathrm{Li}, \mathrm{P}$. He and C. Yu, Tetrahedron, 2012, 68, 4138.

18 A. R. Moosavi-Zare, M. A. Zolfigol, S. Farahmand, A. Zare, A. R. Pourali and R. Ayazi-Nasrabadi, Synlett, 2014, 25, 193.

19 E. Tabrizian, A. Amoozadeh, S. Rahmani, E. Imanifar, S. Azhari and S. Malmir, Chin. Chem. Lett., 2015, 26, 1278.

20 B. Maleki, D. Azarifar, H. Veisi, S. F. Hojati, H. Salehabadi and R. N. Yami, Chin. Chem. Lett., 2010, 21, 1346.

21 M. A. Zolfigol, F. Karimi, M. Yarie and M. Torabi, Appl. Organomet. Chem., 2018, 32, 4063.

22 M. Wang, Z. Yang, Z. Song and Q. Wanga, J. Heterocycl. Chem., 2015, 52, 907.

23 (a) A. Magyar and Z. Hell, Synlett, 2019, 30, 89; (b) Y. Horino, M. Sugata, I. Mutsuura, K. Tomohara and H. Abe, Org. Lett., 2017, 19, 5968; (c) H. G. O. Alvim, J. R. Correa, J. A. F. Assumpcão, W. A. da Silva, M. O. Rodrigues, J. L. de Macedo, M. Fioramonte, F. C. Gozzo, C. C. Gatto and B. A. D. Neto, J. Org. Chem., 2018, 83, 4044; (d) L. S. Longo Jr and M. V. Craveiro, J. Braz. Chem. Soc., 2018, 29, 1999; (e) G. Kumar, E. Nikolla, S. Linic, J. W. Medlin and M. J. Janik, ACS Catal., 2018, 8, 3202; (f) Z. Long, L. Mao, M. Liu, Q. Wan, Y. Wan, X. Zhang and Y. Wei, Polym. Chem., 2017, 8, 5644; (g) G. L. Wu and Q. P. Wu, Adv. Synth. Catal., 2018, 360, 1949. 
24 W. Zhao and J. Sun, Chem. Rev., 2018, 118, 10349.

25 (a) N. Shindoh, K. Kitaura, Y. Takemoto and K. Takasu, J. Am. Chem. Soc., 2011, 133, 8470; (b) K. Inanaga, K. Takasu and M. Ihara, J. Am. Chem. Soc., 2005, 127, 3668; (c) Y. Yoshii, T. Otsu, N. Hosokawa, K. Takasu, K. Okano and H. Tokuyama, Chem. Commun., 2015, 51, 1070.

26 (a) Y. Zhao, Y. Hu, C. Wang, X. Li and B. Wan, J. Org. Chem., 2017, 82, 3935; (b) Y. Zhao, Y. Hu, X. Li and B. Wan, Org. Biomol. Chem., 2017, 15, 3413.

27 (a) K. M. Reddy, E. Bhimireddy, B. Thirupathi, S. Breitler, S. Yu and E. J. Corey, J. Am. Chem. Soc., 2016, 138, 2443; (b) B. Thirupathi, S. Breitler, K. M. Reddy and E. J. Corey, J. Am. Chem. Soc., 2016, 138, 10842; (c) S. Ponra, M. R. Vitale, V. Michelet and V. Ratovelomanana-Vidal, J. Org. Chem., 2015, 80, 3250 .

28 T. Azuma, Y. Takemoto and K. Takasu, Chem. Pharm. Bull., 2011, 59, 1190.

29 R. Fuchigami, K. Namba and K. Tanino, Tetrahedron Lett., 2012, 53, 5725.

30 W. Zhao, Z. Wang and J. Sun, Angew. Chem., Int. Ed., 2012, $51,6209$.

31 Y. Wang, L. J. Song, X. Zhang and J. Sun, Angew. Chem., Int. Ed., 2016, 55, 9704.
32 M. S. Azizi and J. Cossy, Synlett, 2018, 29, 2417.

33 (a) W. Gati and H. Yamamoto, Chem. Sci., 2016, 7, 394; (b) H. Y. Bae and B. List, Chem.-Eur. J., 2018, 24, 13767.

34 (a) S. Nomiyama and T. Tsuchimoto, Adv. Synth. Catal., 2014, 356, 3881; (b) T. E. Rose, B. H. Curtin, K. V. Lawson, A. Simon, K. N. Houk and P. G. Harran, Chem. Sci., 2016, 7, 4158.

35 J. C. T. Reddel, W. Wang, K. Koukounas and R. J. Thomson, Chem. Sci., 2017, 8, 2156.

36 F. Ding, R. William, F. Wang and X. W. Liu, Chem. Commun., 2012, 48, 8709.

37 W. Zhao, H. Qian, Z. Li and J. Sun, Angew. Chem., Int. Ed., 2015, 54, 10005.

38 A. Jolit, S. Vazquez-Rodriguez, G. P. A. Yap and M. A. Tius, Angew. Chem., Int. Ed., 2013, 52, 11102.

39 M. M. Heravi, K. Bakhtiari, Z. Daroogheha and F. F. Bamoharram, Catal. Commun., 2007, 8, 1991.

40 L. Nagarapu, Aneesa, R. Peddiraju and S. Apuri, Catal. Commun., 2007, 8, 1973.

41 M. R. M. Shafiee and R. Moloudi, J. Chem. Res., 2011, 35, 294.

42 Y. M. Ren and C. Cai, Monatsh. Chem., 2009, 140, 49.

43 S. Tu, T. Li, F. Shi, F. Fang, S. Zhu, X. Wei and Z. Zong, Chem. Lett., 2005, 34, 732. 